Original Article

\title{
Cardioprotective and antioxidant effects of taxifolin and vitamin C against diazinone-induced myocardial injury in rats
}

\author{
Shahad Mohammed Najeb ${ }^{1}$ (i) ,Ausama Ayob Jaccob ${ }^{2, *}$ (iD , Muhsin S.G. AL-Moziel ${ }^{3}$, Hayder Mohammed Abdulhameed \\ 4 (iD) \\ ${ }^{1}$ B.SC. pharmacy, Basrah Health Directory \\ ${ }^{2}$ Ph.D. in pharmacology and toxicology, Professor in college of pharmacy, Basrah university, Department of pharmacology \\ and toxicology, Basrah, Iraq \\ ${ }^{3}$ Ph.D. in physiology, Prof. Ass. in college of pharmacy, Basrah university, Department of pharmacology and toxicology, \\ Basrah, Iraq \\ ${ }^{4}$ B.SC. pharmacy, Basrah Health Directory \\ *Correspondence: Ausama1979@yahoo.com
}

Received: July 02, 2021 Accepted: January 04, 2022

\begin{abstract}
In Iraq, excessive exposure to insecticides is increasingly becoming uncontrollable, the objective of this work was to assess the possible ameliorative role of taxifolin and vitamin c against diazinon-induced myocardial injury in rats. 36 sprague female rats divided into 6 groups of 6 rats each. Group 1 received diazinone $20 \mathrm{mg} / \mathrm{kg}$ gavaged for 30 days. Group 2 received taxifolin $(25 \mathrm{mg} / \mathrm{kg})$ and vitamin $C(100 \mathrm{mg} / \mathrm{kg})$ co-administered together and gavaged daily for 30 days before oral diazinone $(20 \mathrm{mg} / \mathrm{kg})$. Group 3 and group 4 were treated with taxifoline $(25 \mathrm{mg} / \mathrm{kg})$ and vitamin C (100 $\mathrm{mg} / \mathrm{kg}$ ) respectively, gavaged separately for 30 days before diazinone $(20 \mathrm{mg} / \mathrm{kg})$ administration. group 5 was considered as control 1 received taxifolin $(25 \mathrm{mg} / \mathrm{kg})$ and vitamin C (100 mg $/ \mathrm{kg})$ co-administered together and gavaged daily for 30 days. The last group, group 6 considered as control 2 which received vehicle of diazinon. Rats' weights, water and food intake were measured and the general vital signs of rats were observed and noted. At the end of study, rats are sacrificed, blood withdrawn for biochemical analysis and heart were excised for glutathione peroxidase and pathological evaluation. Significant increase in body weights in all treated and control groups except group 1. Troponin, LDH, AST and ALT levels were significantly increased in group 1 revealing the existence of ischemia and damage in hearts. Treatment with taxifolin and vitamin $\mathrm{C}$ combination reduced their levels significantly to concentrations comparable to that in the control groups. Such finding supported by histopathological observation. Moreover, this study showed that diazinon administration significantly deteriorated lipid profile, co-administration of taxifolin and vitamin $\mathrm{C}$ was resulted in a significant improvement in lipid profile associated with increased in glutathione peroxidase values showing significant improvement in antioxidant levels. Sub-acute administration of pharmacological doses of taxifolin and vitamin $C$ exerts cardioprotective effects against diazinon-induced myocardial injury in rats.
\end{abstract}

Keywords: Diazinone, Taxifolin, Vitamin C, Antioxidants, Cardiotoxicity

\section{Introduction}

In Iraq, excessive exposure to insecticides and harmful organic chemicals is increasingly becoming uncontrollable, posing environmental hazards that contribute to many medical conditions, including cardiovascular disease and endocrine disorders [1]. Chronic exposure to organophosphorus residue from insecticides could be encountered in food, water, soil, and other products [2]. Diazinon is an organophosphorus insecticide with a wide range of toxicity affecting physiological functions leading to pathological and biochemical changes in multiple tissues, including the kidneys, liver, brain, heart, and testes. Free radicals generation, oxidative stress, and inhibition of acetylcholinesterase enzyme are the most common mechanisms by which diazinon exerts its toxicity on these tissues [3].

The odd electrons in bonding orbital's of diazinon make phospholipids degradation and lipid peroxidation leading to cell damage [4]. Increasing evidence proposes that oxidative stress is an apoptotic stimulant in cardiovascular disorders. Furthermore, lipid peroxidation and diazinon accumulation in heart tissue leading to myocardial involvement may include necrosis and toxic myocarditis [2,5]. It was documented that long term exposure to pesticides increases the risk of coronary thrombosis by diminishing paraoxonase activity [1]. 
For their antioxidative properties and scavenging capacities of free radicals, herbal supplements are considered one of the effective productsin the protection against cardiovascular and renal diseases. Citrus flavonoids have multiple benefits, including free radical scavenging, anti-inflammatory, and cytoprotective property [6]. Taxifolin is a flavonoid (dihydroquercetin) established in Pseudotsuga taxifolia, Dahurian larch, and syn Larix Turoz. It is also present in onions, citrus fruits, milk thistle, and pine bark [7,8]. Taxifolin exerts anti-inflammatory, antioxidant, anticancer, anti-Alzheimer, antimicrobial, antiangiogenic, anti-anaphylaxis, anticoagulation, hepato- and cardioprotective activities [8]. An in vivo mice study demonstrated that taxifolin administration protects against cardiac hypertrophy and ameliorates pressure overloadinduced fibrosis [9].

Vitamin C (ascorbic acid) presents in two forms D-and L-ascorbic acid, vitamin C is considered as a reducing agent for its ability to donate an electron, free radical scavenging, and increase in the synthesis of nitric oxide-thus, plays an essential function in the prevention of cardiovascular disorders [10,11].

The objective of this work was to assess the possible ameliorative role of taxifolin and vitamin $\mathrm{C}$ against diazinon-induced myocardial injury in rats.

\section{Materials and Methods Materials}

Diozinon 10 EC (endimaj for specialized chemical \& pharmaceutical industries Co/Jordan), as formulation containing $10 \%$ active ingredient diluted in corn oil for the final concentration as emulsion. TAXIFOLINE $10 \mathrm{mg}$ (super smart Co./UK), vitamin C (ALPHA CHEMIKA/India). Taxifolin is available as tablets dissolved in water and diluted to final concentrations.

\section{Methods}

After adaptation period, thirty-six Sprague female rats (weighed 180-270 mg) were purchased from Kufa university, college of science were involved in the study. Animals were placed in a plastic cage with sawdust bedding in three animals per one cage ratio. The study was undertaken in normal laboratory conditions of temperature of $25 \pm 3$ and humidity, with $12 \mathrm{hr}$ light /12 hr dark cycle and fed a pellet diet and supplied drinking water at all time. The rats were divided into 6 groups of 6 rats each. Group 1 represented the induced group for diazinone toxicity on the heart (diazinone $20 \mathrm{mg} / \mathrm{kg})$ and gavaged for 30 days. Group 2 received taxifoline $(25 \mathrm{mg} / \mathrm{kg})$ and vitamin C (100 mg $/ \mathrm{kg})$ co-administered together and gavaged daily for 30 days before oral administration of diazinone $(20 \mathrm{mg} / \mathrm{kg})$. Group 3 and group 4 were treated with taxifoline $(25 \mathrm{mg} / \mathrm{kg})$ and vitamin C $(100 \mathrm{mg} / \mathrm{kg})$ respectively, gavaged separately for 30 days before diazinone $(20 \mathrm{mg} / \mathrm{kg})$ administration. Group 5 was considered as control 1, i.e., a comparison group to exclude the effects of protective compounds. The rats in the control group received taxifoline $(25 \mathrm{mg} / \mathrm{kg})$ and vitamin $\mathrm{C}(100 \mathrm{mg} / \mathrm{kg})$ co-administered together and gavaged daily for 30 days. The last group, group 6 considered as control 2 which received corn oil and distilled water as vehicle in volume equal to amount used for dilution of substances gavaged to the remaining groups for 30 days.

The weights were measured at the starting point of the experiment using animal balance and then every week until they were sacrificed. Water and food intake were measured daily for 30 days and the general vital signs of rats were observed and noted. At the end of study (31 days), rats are sacrificed, followed by blood withdrawal and serum collection for biochemical analysis. Serum concentrations of troponin as cardiac biomarker was measured using Roche Combase 411 based on a sandwich test principle, and the results are determined via a calibration curve, lactate dehydrogenase (LDH), creatine kinase (CK), alanine aminotransferase (ALT), aspartate aminotransferase (AST), and lipid profile were measured via the spectrophotometric techniqueusing a COBAS INTEGRA® 400 plus. The heart was excised and divided into two parts, one half digested for glutathione peroxidase measurements as antioxidant indicator which was homogenized using a specialized homogenizer with $9 \mathrm{~mL}$ buffer phosphate ( $\mathrm{pH} 7.4$ ) appropriate for $1 \mathrm{~g}$ tissue pieces (according to instructions from rat glutathione peroxidase [Gpx1] kit; catalogue no. RDEER0274) using the ELIZA technique while the other half for pathological evaluation. Rat hearts were fixed in $10 \%$ formalin, sectioned, and embedded in paraffin; then sectioned to $4-5$ $\mu \mathrm{m}$ andstained using hematoxylin and eosin stain for investigation under a microscope for evaluation of myocardial ischemic parts and heart damage.

\section{Ethical statement}

Experiments were performed in compliance with the National Institute of Health Guidelines for the Treatment and Use of Laboratory Animals (86/609/EEC) and approved by the college of pharmacy / Basrah university, ethics committee.

\section{Statistical analysis}

The results are expressed as Mean \pm SEM. One way analysis of variance with Tukey post hoc analysis to compare test groups with control groups. Values are considered significantly different at $p<0.05$. The analysis was carried out using GraphPad Prism software (Version 7). 


\section{Results}

Abnormal signs and behaviors were reported in rats within each study group. Different symptoms of cholinergic toxicity were observed in the intoxicated group 1, e.g., fatty diarrhea associated with abnormal color stool, frequent urination, reduction in general movement, and reduction in food intake-especially in the last days of the study period. Significant increase in body weights, when compared changes in body weights in each rat group separately, in all treated and control groups (except for diazinon administered group [group 1], were no significant differences were observed with p-value 0.1158 . In contrast, decrease in body weights in group 1 clearly observed after two weeks from the starting point since it was associated with reduction in food intake and deterioration in general health (Figure 1).

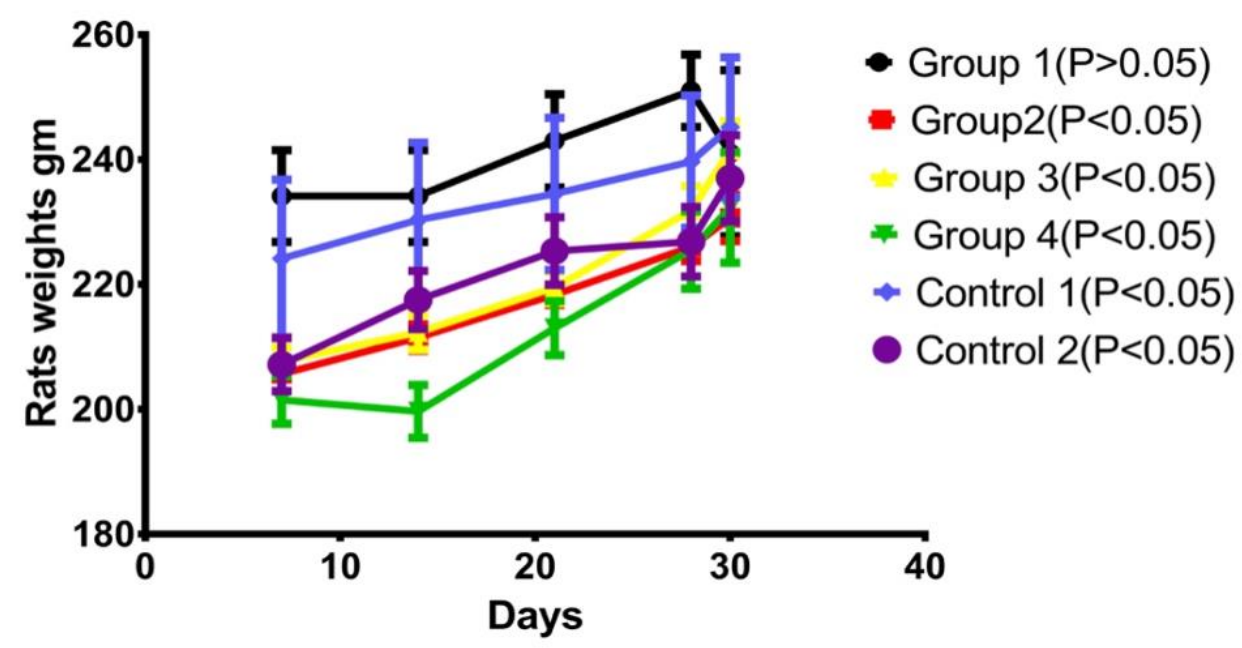

Figure 1. Changes in rats weights of the diazinon, test and control groups. Values are expressed as Mean \pm SEM in each group.

For evaluation of heart injury induced by diazinon and the cardioprotective role of taxifolin and vitamin C, serum concentrations of some enzymes and heart biomarkers were assessed. Following diazinon administration, serum troponin level was significantly increased revealing the existence of ischemia in group 1 . Treatment with taxifolin and vitamin $C$ combination reduced troponin level significantly to concentrations comparable to that in the control groups. When separately administered: Taxifolin in group 3 and vitamin $C$ in group 4, serum troponin levels were reduced significantly, exhibiting some protection against diazinon-induced heart damage, which was highly significant compared to the control groups. Diazinon led to a significant increase in serum LDH compared to remaining groups (except in group 4 [pretreated with vitamin C] which showed no significant reduction in serum LDH level) as seen in Figure 2. 

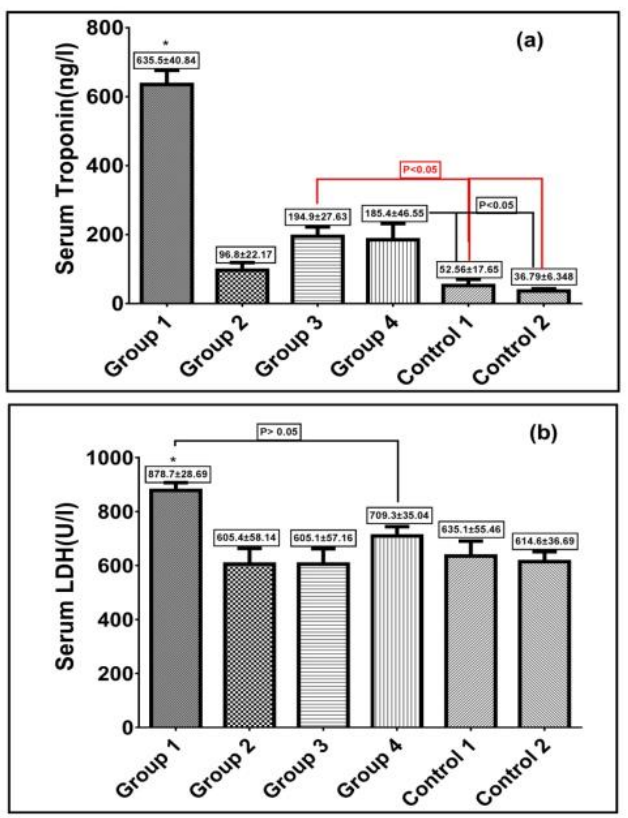

Figure 2. (a) Effect of txifolin and /or vitamin $C$ on serum troponin levels after diazinon induced toxicity in rats. Red bar reperesent that group 3 significantly different compared to control groups; (b) Effect of taxifolin and /or vitamin C on serum LDH levels after diazinon induced toxicity in rats. Values are expressed as Mean \pm SEM in each group. * Represent that group 1 significantly high in both (troponin and LDH) compared to remaining groups $\mathrm{P}<0.05$.

Serum AST and ALT are useful biochemical indicators for cardiotoxicity. Diazinon administration in group 1 significantly increased their levels compared to the control groups. However, taxifolin and vitamin $\mathrm{C}$ administration dropped their levels to values comparable to the control groups. Nevertheless, there was no significant changes in serum creatine kinase in all test and control groups as shown in Figure 3.
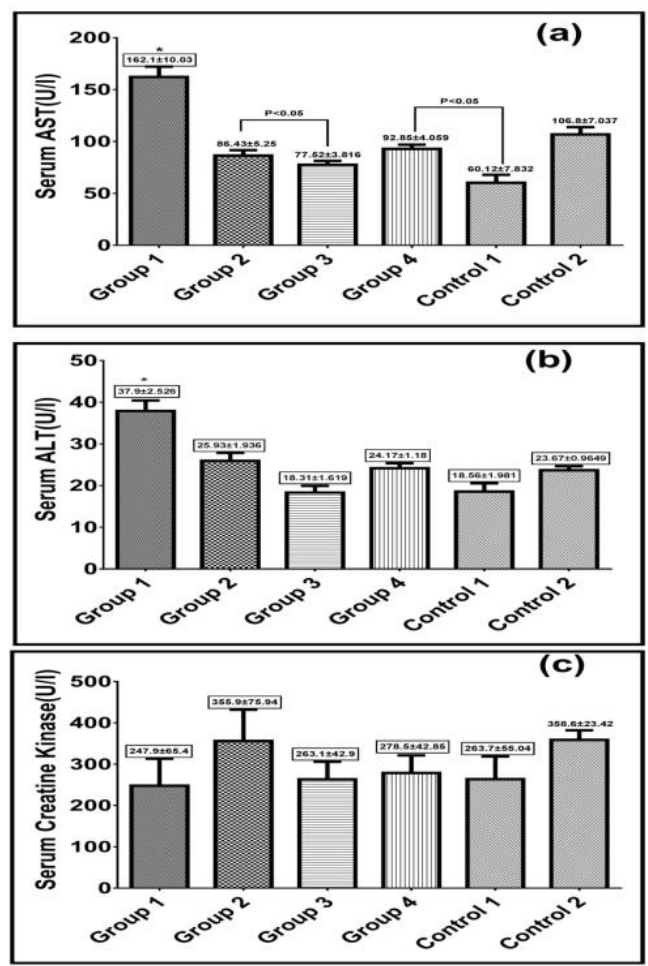

Figure 3. Effect of taxifolin and/or vitamin C on serum aspartate aminotransferase (AST) levels(a), serum alanine aminotransferase(ALT) levels(b) and serum creatine kinase levels (c) after diazinon induced toxicity in rats. Values are expressed as Mean \pm SEM in each group. ${ }^{*}$ Represent significant difference compared to remaining groups $\mathrm{P}<0.05$. 
Regarding histopathological change in the heart, (figure4) showed that diazinon induce myocyte damage occurs with severe degeneration (myocytosis) and vaculation of nuclei. As well as disruption of the sarcolemma was observed. Fortunately, co administration of taxifolin and vitamin $C$ together showed significant protection associated with central nuclei and striated myocardium muscle fibers. Little myocardium fibers and sarcolemma are thickening may be noticed compared with control groups. In spite of administration of taxifolin or vitamin $C$ separately showed some protection but still observed clear area of myocardial degeneration and vaculation especially in group 4 compared with control groups that showed normal architecture structure of myocyte and nucleus.
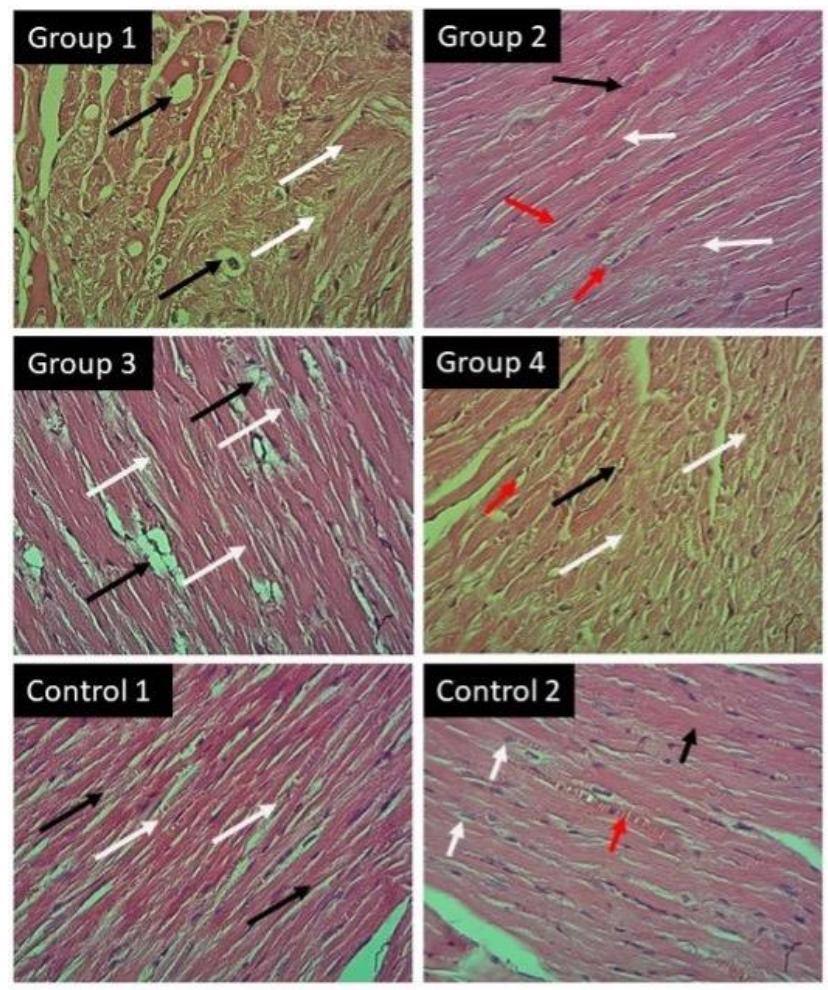

Figure4. Light micrograph of heart with H\&E x40: Group 1 shows missive degeneration of myocardium (white arrow), and vaculation of nucleus (black arrow); Group 2 shows normal striate myocardium fibers (white arrow), central nuclei (black arrow) and sarcolemma (red arrow); Group 3 shows little of myocardium degeneration (white arrow), and vacuolation of nuclei (black arrow); Group 4 shows large area of degeneration (white arrows) and undergoes the nuclei (black arrow) and sacrolemma to vacuolation (red arrow); Group 5 shows normal structures of myocardium (white arrows), and normal sarcolemma (black arrows); Group 6 shows normal myocardium architecture, striated myocyte (white arrows) and central nucleus (black arrow) and sarcolemma (red arrow).

Moreover, this study showed that diazinon administration significantly deteriorated lipid profile, represented by increased LDL; increased total cholesterol; and deceased HDL. However, VLDL and triglyceride levels were not significantly affected (Table 1). Co-administration of taxifolin and vitamin $C$ was resulted in a significant improve in lipid profile of study rats by decreasing LDL and increasing HDL levels. However, administration of the taxifolin or vitamin $C$ separately decreased LDL levels significantly; yet, higher than the control groups. 
Table 1. Effect of taxifolin and /or vitamin $\mathrm{C}$ on lipid profile after diazinon induced toxicity in rats.

\begin{tabular}{cccccc}
\hline Groups & $\begin{array}{c}\text { LDL }(\mathrm{mg} / \mathrm{dl}) \\
\text { Mean } \pm \text { SEM }\end{array}$ & $\begin{array}{c}\text { VLDL }(\mathrm{mg} / \mathrm{dl}) \\
\text { Mean } \pm \text { SEM }\end{array}$ & $\begin{array}{c}\text { HDL }(\mathrm{mg} / \mathrm{dl}) \\
\text { Mean } \pm \text { SEM }\end{array}$ & $\begin{array}{c}\text { Chol (mg/dl) } \\
\text { Mean } \pm \text { SEM }\end{array}$ & $\begin{array}{c}\text { TG (mg/dl) } \\
\text { Mean } \pm \text { SEM }\end{array}$ \\
\hline Group 1 & $13.41 \pm 0.50^{* *}$ & $9.643 \pm 1.24$ & $24.03 \pm 1.59^{*}$ & $85 \pm 2.214^{*}$ & $48.22 \pm 6.22$ \\
Group 2 & $8.443 \pm 0.29$ & $10.31 \pm 0.59$ & $45.49 \pm 1.94$ & $67.72 \pm 3.427$ & $51.54 \pm 2.98$ \\
Group 3 & $10.01 \pm 0.38^{*}$ & $12.21 \pm 1.02$ & $38.2 \pm 2.30$ & $65.7 \pm 4.095$ & $61.05 \pm 5.12$ \\
Group 4 & $12.71 \pm 0.36^{*}$ & $9.903 \pm 0.32$ & $47.35 \pm 3.31$ & $67.8 \pm 1.735$ & $49.51 \pm 1.64$ \\
Control 1 & $7.05 \pm 0.36$ & $9.843 \pm 0.78$ & $38.42 \pm 2.53$ & $63.56 \pm 4.239$ & $49.22 \pm 3.92$ \\
Control 2 & $6.907 \pm 0.52$ & $11.58 \pm 0.83$ & $46.41 \pm 5.23$ & $66.72 \pm 5.506$ & $57.9 \pm 4.15$ \\
P value & $<\mathbf{0 . 0 0 1}$ & $\mathbf{0 . 2 0 6 9}$ & $<\mathbf{0 . 0 5}$ & $<\mathbf{0 . 0 5}$ & $\mathbf{0 . 4 0 1 6}$ \\
\hline
\end{tabular}

Values are expressed as Mean \pm SEM in each group. different characters represent highly significant difference compared to remaining groups. ${ }^{*} \mathrm{p}<0.05,{ }^{* *} \mathrm{P}<0.001$

Figure 5 shows levels of heart glutathione preoxidase by study groups. Administration of diazinon significantly decreased glutathione preoxidase in group 1. Taxifolin and vitamin C increased glutathione preoxidase values showing significant improvement in antioxidant levels in all test and control groups, with the highest level observed in control 1.

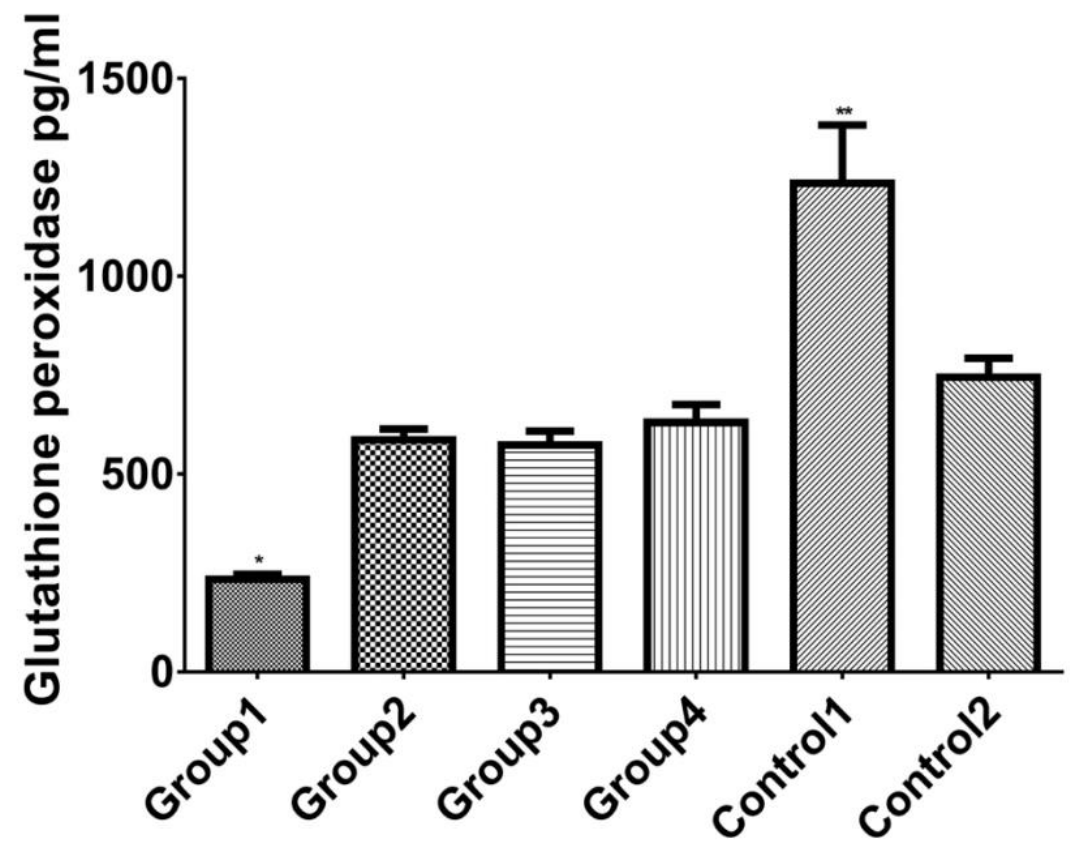

Figure 5. Effect of taxifolin and /or vitamin C on myocardium glutathione peroxidase levels after diazinon induced toxicity in rats. Values are expressed as Mean \pm SEM in each group. ${ }^{*},{ }^{* *}$ represent significant difference between groups.

\section{Discussion}

Diazinon shows their toxicity upon entering the body and metabolizing to highly toxic Oxon intermediate metabolites. These metabolites result insignificant heart damage by irreversible inhibition of acetyl choline esterase enzyme resulting in acetylcholine level raise in synaptic cleft which disturbs neurotransmitters balance and subsequent toxicity. Furthermore, lipid peroxidation and decreased antioxidant enzyme are considered the major leading cause of organs toxicity $[12,13]$. This study showed that oral diazinon administration caused significant reduction in body weight and heart weight, especially on the $4^{\text {th }}$ week of the study period. Decrease food intake and generalized weakness are the main signs appeared in group 1 compared to the remaining test groups. This reduction in appetite and food intake with subsequent reduction in rat weight and generalized weakness was found in another study [14].

The present study showed that sub-acute (30 days) oral administration of diazinon in doses equal to $1.6 \%$ of the acute 
Najeb et al. I Cardioprotective effects of taxifolin and vitamin C

LD50 oral dose [15] caused significant heart damage. It was demonstrated that serum troponin level was significantly increased in the diazinon intoxicated group. High serum troponin level is the biomarker of choice for the determination of cardiac injury. Elevated serum troponin concentrations persist after cardiac injury owing to the slow degradation and release of the structural pool [16]. Several studies documented that chronic exposure to organophosphorus insecticides caused pathological changes in heart muscle and increases in free radical generation $[5,14]$.

Our study confirms the role of taxifolin and vitamin $C$ administration on reducing serum troponin level. Significant findings were observed when taxiflolin and vitamin C co-administered as combination. Taxifolin is a powerful antioxidant, owing to phenolic structure, prevents lipid oxidation, delaying toxic product production, and improve cardiac function [17]. Vitamin $\mathrm{C}$ works as an antioxidant and enzyme cofactor, these prevent oxidative LDL changes. Vitamin $\mathrm{C}$ administration decreases plague formation and prevents thrombosis and atherosclerosis. In addition there is an inverse relationship between vitamin $C$ intake and hypertension [18]. In the present study, taxifolin and vitamin $C$ administration showed synergistic effect regarding cardiac protection. Previous studies indicated the use of combinations of flavonoids, polyphenols and vitamins in the prevention of different disorders $[19,20]$.

Serum concentration of AST, ALT, and LDH were significantly increased in diazinon intoxicated group. On the other hand, serum concentration of CK was not significantly changed in all test and control groups. These changes were combined with significant reduction in antioxidant enzyme (glutathione peroxidase) level in cardiac tissues of group 1 (diazinon intoxicated group). Our study collectively confirms the hypothesis that diazinon induce heart muscle damage with significant elevation of serum concentrations of some cardiac biomarkers combined with significant reduction of antioxidant enzyme.

LDH is a biomarker of tissue damage due to its presence in plasma in high concentrations during injuries, such as in myocardial infarction and heart failure. Other markers like CK, which is present mostly in heart cell, skeletal muscle, and renal system was often tested in the serum as an indicator of diseases such as acute kidney injury, rhabdomyolysis and myocardial damage [21]. The increased serum (LDH, AST and ALT) levels of LDH, AST, and ALT in the diazinon treated group (group 1), explains the toxic effects of diazinon on cardiomyocytes. Evidence linking AST and ALT with heart diseases are controversy; however, positive relationship appears to be more likely associated with increased risk of cardiac diseases [22].

Pretreatment with taxifolin and vitamin $\mathrm{C}$ reduced serum concentrations of cardiac biomarkers toward normal levels in magnitudes that are comparable to the control groups. Taxifolin protects against ischemia and cardiac injury by different mechanisms; in this study, we present evidence that taxifolin and vitamin C ameliorate oxidative stress and reduce free radical generation. This evidence was strengthened by previous article [23]. Taxifolin inhibits angiotensin II-production prevent cardiac dysfunction, inhibits platelet aggregation, promotes smooth muscle relaxation, and ameliorates ischemiareperfusion damage in rats through manipulation of NF- $\kappa$ B production [9]. There are growing evidence shows that taxifolin possesses divergent pharmacologic properties including antioxidant, anti-inflammatory, anti-apoptosis, and anti-tumor properties [24]. Several epidemiological articles indicated that dietary or pharmacological intake of vitamin conversely correlates with cardiovascular disease and hypertension [11]. Increase production of nitrous oxide and free radical scavenger are the major mechanisms involved in cardiac protection by vitamin C [25].

Administration of taxifolin and vitamin $C$ alleviates the toxicity and decrease serum concentration of cardiac biomarkers. Many articles support the evidence that flavonoids ameliorate or protect the heart against diazinon toxicity. For example, chrysin and crocin are natural flavonoids improve cardiac and hematological markers induced by diazinon toxicity; administration of nigella sativa decreases diazinon cardiotoxic effect; silibinin and vitamin E alleviates diazinon induced cardiotoxicity through antioxidative properties; and glycyrrhizin demonstrated beneficial role against diazinon induced toxicity $[2,3,26-28]$.

Deterioration of lipid profile expressed as an elevation of total serum cholesterol, increased LDL, and decreased serum HDL was seen in diazinon treated group. Administration of taxifolin and vitamin $\mathrm{C}$ alleviates and protects against deterioration were significant reduction in LDL and significant increase in HDL were observed. In similar finding, Ibrahim et al conclude that diazinon interferes negatively with lipid profile [29]. Nevertheless, Zeinali et al found an increase in serum HDL after sub-acute diazinon administration [26]. Sub-acute administration of polyphenols, vitamins, and other antioxidants are associated with significant improvement in lipid profile [26,30]. Our study showed that diazinon administration alone caused a significant reduction in heart glutathione peroxidase level inducing oxidative stress and tissue damage. Taxifolin and vitamin C administration increased glutathione peroxidase level decreasing free radical generation and protect against diazinon induce heart damage. Our findings are in agreement with results obtained by Basarslan et al and Danaei et al where levels of antioxidant enzymes returned towards normal levels, thus emphasizing an antioxidant effect of taxifolin and vitamin C [27,31].

\section{Conclusions}

Sub-acute administration of pharmacological doses of taxifolin and vitamin C exerts cardioprotective and antioxidant effects against diazinon-induced myocardial injury in rats. 


\section{Acknowledgement}

The work was abstracted from MSC thesis submitted to the college of pharmacy, Basrah university/ department of pharmacology and toxicology. Authors thank the college for continuous support.

\section{Conflict of interest}

No think declared.

\section{CRediT author statement}

SMN: Experimentation, Visualization, Results compilation; AAJ: Writing Original draft preparation, Editing, Supervision, Data curation and Formal analysis; MS.G. A: Methodology, Investigation; HMA: Resources, Software.

\section{ORCID}

Shahad Mohammed Najeb: 0000-0002-3486-0573

Ausama Ayob Jaccob: 0000-0002-1433-6731

Hayder Mohammed Abdulhameed:0000-0003-3751-6011

\section{References}

[1] Mostafalou S, Abdollahi M. Pesticides and human chronic diseases: evidences, mechanisms, and perspectives. Toxicol appl pharmacol 2013;268(2):157-177. http://dx.doi.org/10.1016/j.taap.2013.01.025

[2] Razavi BM, Hosseinzadeh H, Movassaghi AR, Imenshahidi M, Abnous K. Protective effect of crocin on diazinon induced cardiotoxicity in rats in subchronic exposure. Chem Biol Interact 2013;203(3):547-555.

http://dx.doi.org/10.1016/j.cbi.2013.03.010

[3] Beydilli H, Yilmaz N, Cetin ES, Topal Y, Celik OI, Sahin C, et al. Evaluation of the protective effect of silibinin against diazinon induced hepatotoxicity and free-radical damage in rat liver. Iran Red Crescent Med J 2015;17(4). https://doi.org/10.5812/ircmj.17(4)2015.25310

[4] Bhatti GK, Sidhu IPS, Saini NK, Puar SK, Singh G, Bhatti JS. Ameliorative role of melatonin against cypermethrin induced hepatotoxicity and impaired antioxidant defense system in Wistar rats. IOSR J Environ Sci Toxicol Food Technol 2014;8(1):39-48.

[5] Anand S, Singh S, Nahar Saikia U, Bhalla A, Paul Sharma Y, Singh D. Cardiac abnormalities in acute organophosphate poisoning. Clin Toxicol 2009;47(3):230-235. https://doi.org/10.1080/15563650902724813

[6] Mahmoud AM, Hernández Bautista RJ, Sandhu MA, Hussein OE. Beneficial effects of citrus flavonoids on cardiovascular and metabolic health. Oxid Med Cell Longev 2019;2019:1-19. https://doi.org/10.1155/2019/5484138

[7] Sun X, Chen RC, Yang ZH, Sun GB, Wang M, Ma XJ, et al. Taxifolin prevents diabetic cardiomyopathy in vivo and in vitro by inhibition of oxidative stress and cell apoptosis. Food Chem Toxicol 2014;63:221-232.

http://dx.doi.org/10.1016/j.fct.2013.11.013

[8] Sunil C, Xu B. An insight into the health-promoting effects of taxifolin (dihydroquercetin). Phytochemistry 2019;166:112066. https://doi.org/10.1016/j.phytochem.2019.112066

[9] Guo H, Zhang X, Cui Y, Zhou H, Xu D, Shan T, et al. Taxifolin protects against cardiac hypertrophy and fibrosis during biomechanical stress of pressure overload. Toxicol Appl Pharmacol 2015;287(2):168-177.

http://dx.doi.org/10.1016/j.taap.2015.06.002

[10] Wilson JX. Regulation of vitamin C transport. Annu Rev Nutr 2005;25:105-125. https://doi.org/10.1146/annurev.nutr.25.050304.092647

[11] Ellulu MS. Obesity, cardiovascular disease, and role of vitamin C on inflammation: a review of facts and underlying mechanisms. Inflammopharmacology 2017;25(3):313-328. https://doi.org/10.1007/s10787-017-0314-7

[12] Giordano G, Afsharinejad Z, Guizzetti M, Vitalone A, Kavanagh TJ, Costa LG. Organophosphorus insecticides chlorpyrifos and diazinon and oxidative stress in neuronal cells in a genetic model of glutathione deficiency. Toxicol Appl Pharmacol. 2007;219(2-3):181-9. https://doi.org/10.1016/j.taap.2006.09.016. 
Najeb et al. I Cardioprotective effects of taxifolin and vitamin C

[13] Abdou HM, El Mazoudy RH. Oxidative damage, hyperlipidemia and histological alterations of cardiac and skeletal muscles induced by different doses of diazinon in female rats. J Hazard Mater 2010;182(1-3):273-278. http://dx.doi.org/10.1016/j.jhazmat.2010.06.026

[14] Ogutcu A, Uzunhisarcikli M, Kalender S, Durak D, Bayrakdar F, Kalender Y. The effects of organophosphate insecticide diazinon on malondialdehyde levels and myocardial cells in rat heart tissue and protective role of vitamin E. Pestic Biochem Physiol 2006;86(2):93-98. https://doi.org/10.1016/j.pestbp.2006.01.010

[15] World Health Organization. The WHO recommended clasification of pesticides by hazard and guidelines to classification 2019;2020.

[16] Babuin L, Jaffe AS. Troponin: The biomarker of choice for the detection of cardiac injury. CMAJ 2005;173(10):1191-202. https://doi.org/10.1503/cmaj/051291

[17] Topal F, Nar M, Gocer H, Kalin P, Kocyigit UM, Gülçin I, et al. Antioxidant activity of taxifolin: an activity-structure relationship. Journal of enzyme inhibition and medicinal chemistry 2016;31(4):674-683.

https://doi.org/10.3109/14756366.2015.1057723

[18] Moser MA, Chun OK. Vitamin C and heart health: a review based on findings from epidemiologic studies. Int J Mol Sci 2016;17(8):1328. https://doi.org/10.3390/ijms17081328

[19] McAnulty SR, Nieman DC, McAnulty LS, Lynch WS, Jin F, Henson DA. Effect of mixed flavonoids, n-3 fatty acids, and vitamin $\mathrm{C}$ on oxidative stress and antioxidant capacity before and after intense cycling. Int J Sport nutr exerc metab 2011;21(4):328-337. https://doi.org/10.1123/ijsnem.21.4.328

[20] Abdulidha NA, Jaccob AA, AL-Moziel MSG. Protective effects of Co-Q10, ginkgo biloba, and l-carnitine on brain, kidney, liver, and endocrine system against sub-acute heavy metals toxicity in male rats. Toxicol and Environ Health Sci 2020;12(4):331-341. https://doi.org/10.1007/s13530-020-00061-7

[21] Richards et al. 乳鼠心肌提取 HHS Public Access. Physiol Behav. 2018;176:139-48.

[22] Ndrepepa G, Kastrati A. Alanine aminotransferase-a marker of cardiovascular risk at high and low activity levels. J Lab Precis Med 2019;4(4):29. http://dx.doi.org/10.21037/jlpm.2019.08.01

[23] Balci MG, Eken H, Gulaboglu M. The effect of taxifolin in the treatment of renal damage induced by ischemia reperfusion in rats. Eurasian J Med Investig 2019;3(2):150-155. https://www.ejmi.org/10.14744/ejmi.2019.60151/

[24] Wang YH, Wang WY, Chang CC, Liou KT, Sung YJ, Liao JF, et al. Taxifolin ameliorates cerebral ischemia-reperfusion injury in rats through its anti-oxidative effect and modulation of NF-kappa B activation. J Biomed Sci 2006;13(1):127-141. http://dx.doi.org/10.1007\%2Fs11373-005-9031-0

[25] Sherman DL, Keaney Jr JF, Biegelsen ES, Duffy SJ, Coffman JD, Vita JA. Pharmacological concentrations of ascorbic acid are required for the beneficial effect on endothelial vasomotor function in hypertension. Hypertension 2000;35(4):936941. https://doi.org/10.1161/01.HYP.35.4.936

[26] Zeinali M, Meybodi NT, Rezaee SA, Rafatpanah H, Hosseinzadeh H. Protective effects of chrysin on sub-acute diazinoninduced biochemical, hematological, histopathological alterations, and genotoxicity indices in male BALB/c mice. Drug Chem Toxicol 2018;41(3):270-280. https://doi.org/10.1080/01480545.2017.1384834

[27] Danaei GH, Memar B, Ataee R, Karami M. Protective effect of thymoquinone, the main component of Nigella Sativa , against diazinon cardio-toxicity in rats. Drug Chem Toxicol 2019;42(6):585-591.

https://doi.org/10.1080/01480545.2018.1454459

[28] Karimani A, Heidarpour M, Moghaddam Jafari A. Protective effects of glycyrrhizin on sub-chronic diazinon-induced biochemical, hematological alterations and oxidative stress indices in male Wistar rats. Drug and chem toxicol 2019;42(3):300-308. https://doi.org/10.1080/01480545.2018.1497053

[29] Ibrahim NA, El-gamal BA. Effect of diazinon, an organophosphate insecticide, on plasma lipid constituents in experimental animals. BMB Reports 2003;36(5):499-504. https://doi.org/10.5483/BMBRep.2003.36.5.499

[30] Bao L, Hu L, Zhang Y, Wang YI. Hypolipidemic effects of flavonoids extracted from Lomatogonium rotatum. Experimental and therapeutic medicine 2016;11(4):1417-1424. https://doi.org/10.3892/etm.2016.3038 
[31] Basarslan F, Yilmaz N, Ates S, Ozgur T, Tutanc M, Motor VK, et al. Protective effects of thymoquinone on vancomycininduced nephrotoxicity in rats. Hum Exp Toxicol 2012;31(7):726-733. https://doi.org/10.1177\%2F0960327111433185 